\title{
Commercializing Academic Research Results and the Role of Spin-off Companies
}

\author{
Herbert Reutimann*
}

\begin{abstract}
The commercialization of academic research results is often difficult and requires a flexible approach that depends on the nature of the project. Most technologies are very early-stage and often not mature enough for industry partners or financial investors. Spin-off companies play an important role in this process. Through their activities universities make an important contribution to the innovation capacity of industry.
\end{abstract}

Keywords: Innovation · Licensing · Spin-off company · Technology transfer

Piqur Therapeutics, Synthena and Molecular Partners are just three examples of promising spin-off companies from the Universities of Basel, Bern and Zurich, respectively. While spin-off companies rarely stemmed from Swiss universities 20 years ago, nowadays about one new spinoff is started-up each month solely from one of these three universities (Fig. 1). Moreover, these spin-off companies show a very high survival rate. Benchmarks against leading European or US universities show that the rate of spin-off creation of these three universities compares well relative to their size. ${ }^{[1-3]}$

According to the annual swiTTreport ${ }^{[4]}$ more than 110 spin-off companies were created by Swiss universities within the time span 2010 to 2012. Spin-off companies generally only comprise companies that fulfill the following three criteria: a) they develop or market products based on research results derived from the university, b) the products fall under a license (or another formal IP transfer) of the university, and c) the companies were (co-) founded by current or former employees of the university.

\footnotetext{
${ }^{*}$ Correspondence: H. Reutimann
}

Unitectra, Technology Transfer of the Universities of

Basel, Bern and Zurich

Scheuchzerstrasse 21

$\mathrm{CH}-8006$ Zürich

Tel.: +41446344491

E-mail: reutimann@unitectra.ch
However, some universities also count start-ups rather than only spin-off companies, which leads to higher figures. Such start-ups include companies that have no license from the university, thus their relation to the university might be quite distant, such as a consulting company founded by university graduates that might use knowledge acquired by the founders during their studies at the university. Moreover, technical universities show higher numbers because they harbor application-oriented disciplines that only exist at such institutions, such as various engineering sciences, and which often give rise to spin-off or startup companies. Thus, these factors must be taken into account when comparing the number of spin-offs or start-ups published by different universities.
The main focus of universities in research is on the creation of new scientific knowledge. Research results and inventions elaborated at universities often can be the nucleus of future innovation. However, they typically are far from a marketable product and often require laborious and costly development before reaching the market. In most cases universities are neither suitable nor is it in their interest to undertake such product development. Thus, an industry partner is required that is both interested and able to take over product development under a license from the university. Each year Swiss universities grant about 200 new licenses. ${ }^{[4]}$

A university has various partnering options. Large companies have all the required resources to swiftly develop uni-

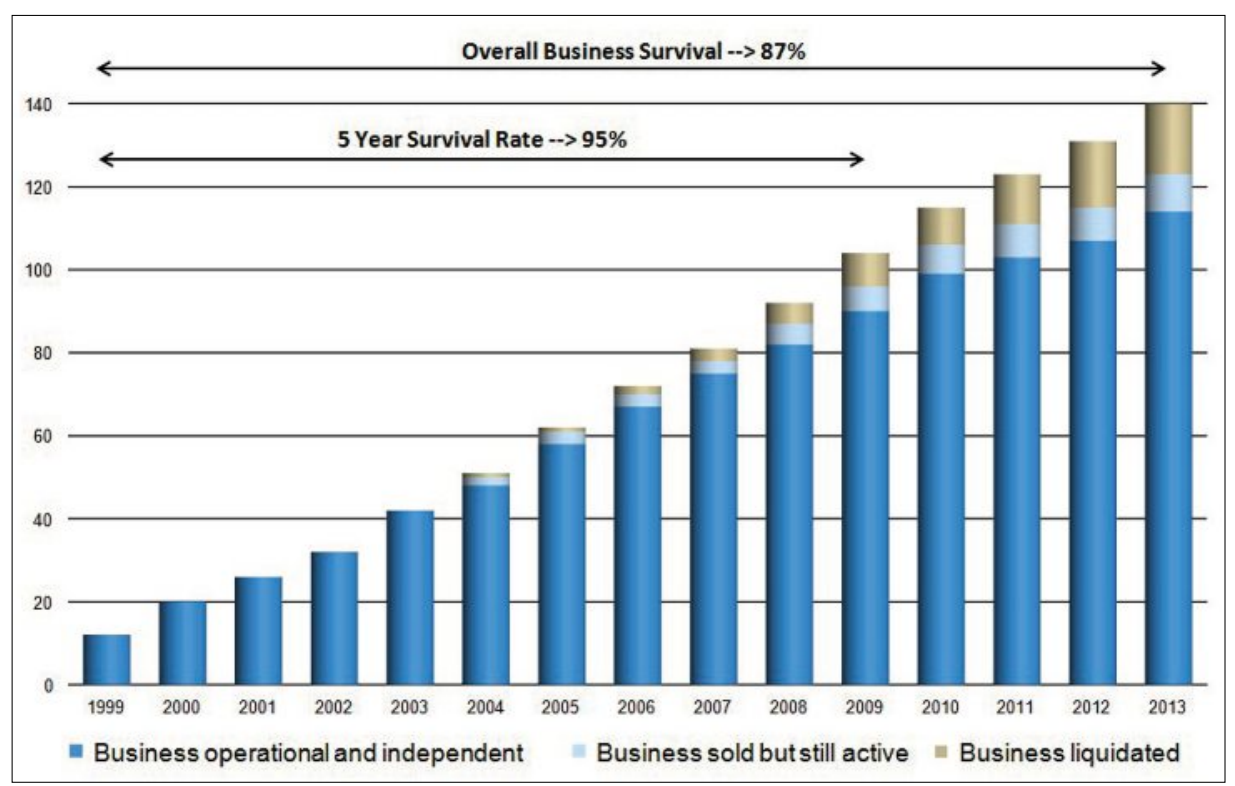

Fig. 1. Number of spin-off companies of the Universities of Basel, Bern and Zurich in the period from 1999 to 2013 (cumulative) and their survival rates. 
versity technologies and successfully market products through existing channels. However, such companies usually have a broad range of other development projects in the pipeline that might compete with university technology. Moreover, large companies have the means to in-license or buy interesting products at a later development stage, in order to minimize development risks.

Small- and medium-sized enterprises (SME) might be more flexible to new opportunities if the necessary resources are available. Moreover, the few development projects established usually gain high attention within an SME and are carried forward as quickly as possible. Furthermore, deals generally can be finalized more quickly due to short decision-making processes. Therefore, SMEs are the most common licensing partners for universities both in Switzerland and abroad. ${ }^{[1,4]}$

Spin-off companies usually focus on a specific technology and all the available resources are bundled, additionally the scientific founders are already thoroughly familiar with the technology. The team has a high motivation to bring forward the particular project because company success fully depends on it. Spin-offs usually offer jobs close to their home university although a few of them also generate a high number of jobs even after several years of operation. Significant management resources in spin-offs are often absorbed by the struggle for enough funding. Shortage on relevant know-how in fields such as product development, regulatory issues and IP might lead to delays or costly mistakes. In the worst case the commercialization of a first-class technology might be impeded due to shortcomings typical for young companies. Spin-off companies have different business models. Whereas some companies are set-up to carry the projects through the whole development process and to market the products, other spin-offs aim at developing a project to a certain stage and then sublicense or sell the specific project or the whole company to a larger enterprise.

Commercializing university technologies thus requires a flexible and balanced approach. Spin-offs often play an important role in bridging the gap between early-stage university technologies and the need for reduced risk development projects favored by larger companies, particularly in the life sciences field. However, other projects might be developed more successfully through licensing to an established company or by partnering them with novel incubation models that were set-up in the past years. Swiss universities only have very limited resources to carry forward and mature early-stage projects, which means that commercially interesting projects regularly are not taken up by an industrial partner or a financial investor and are either stopped completely or experience heavy delays on their way to the market. In many other countries, such as USA, UK and Germany, more and better instruments exist to carry early-stage university technologies towards application, either through public funds at universities or public-private partnership models. Improvements to address this funding gap evident at Swiss universities could have a significant economic impact.

Universities engage in the commercialization of research results for various reasons, most importantly to bring a benefit to the economy and the society in general, for example in the form of a new treatment option for patients suffering from a certain disease. If managed properly and if certain guidelines are followed, the collaboration between universities and industry is fruitful for both parties in different aspects and without having a negative impact on the core values and the interests of academia. License revenues usually represent a minor share of the overall university budgets. However, they are an important incentive for inventors and research groups and are useful for the universities to finance the technology transfer programs and the protection of new intellectual property. Through their activities at the interface to industry, universities play an important role in fostering innovation, both through scientific collaborations and the licensing of academic research results.

Received: September, 2014

[1] Association of University Technology Managers (AUTM), Annual Licensing Surveys and STATT Database (www.autm.net).

[2] University of Cambridge, Cambridge Enterprise, information provided on website ( $w w w$. enterprise.cam.ac.uk).

[3] University of Oxford, Isis Innovation, information provided on website (www.isis-innovation. com).

[4] swiTTreport, editions 2011 to 2013, Ed. swiTT, Swiss Technology Transfer Association, Bern. 